\title{
Decreased HHV-6 IgG in Alzheimer's Disease
}

\author{
Gabriel Westman ${ }^{1 *}$, Jonas Blomberg ${ }^{1}$, Zhibing Yun ${ }^{2}$, Lars Lannfelt ${ }^{3}$, Martin Ingelsson ${ }^{3}$ and \\ Britt-Marie Eriksson ${ }^{1}$
}

'Department of Medical Sciences, Uppsala University, Uppsala, Sweden, ${ }^{2}$ Department of Laboratory Medicine, Karolinska
Institutet, Stockholm, Sweden, ${ }^{3}$ Department of Public Health and Caring Sciences, Uppsala University, Uppsala, Sweden

Human herpesviruses have previously been implicated in the pathogenesis of Alzheimer's disease (AD) but whether they are causal, facilitating, or confounding factors is yet to be established. A total of $50 \mathrm{AD}$ subjects and 52 non-demented (ND) controls were analyzed in a multiplex assay for lgG reactivity toward herpes simplex virus (HSV), varicella zoster virus (VZV), cytomegalovirus (CMV), and human herpesvirus 6 (HHV-6). The HHV-6 IgG reactivity was significantly lower in $A D$ subjects compared to ND controls, whereas there were no differences in HSV, VZV, or CMV antibody levels between the groups. Analysis of peripheral blood mononuclear cells with a subtype-specific HHV-6 PCR revealed no

OPEN ACCESS

Edited by:

Stefano L. Sensi,

University of California Irvine, USA

Reviewed by:

Alberto Granzotto,

Centro Scienze dell'Invecchiamento e Medicina Traslazionale (CeSI-MeT),

Italy

Chaoyang Li, Wuhan Institute of Virology, China

*Correspondence: Gabriel Westman gabriel.westman@medsci.uu.se

Specialty section: This article was submitted to Neurodegeneration, a section of the journal Frontiers in Neurology

Received: 17 November 2016 Accepted: 27 January 2017 Published: 20 February 2017

Citation:

Westman G, Blomberg J, Yun Z,

Lannfelt $L$, Ingelsson $M$ and

Eriksson B-M (2017) Decreased HHV-6 IgG in Alzheimer's Disease.

Front. Neurol. 8:40.

doi: 10.3389/fneur.2017.00040 signs of reactivation, as $A D$ and ND subjects presented with comparable HHV-6 DNA levels in PBMCs, and all positive samples were of subtype B. Whether HHV-6 is a factor in $A D$ remains to be elucidated in future studies.

Keywords: Alzheimer's disease, herpesvirus, HHV-6, multiplex, immunoassay, IgG

\section{INTRODUCTION}

It has been debated whether infectious agents are causing, triggering, or facilitating the most common age-related diseases, such as cardiovascular disease, dementia, diabetes, and cancer. Well-proven examples include human papillomavirus, causing the majority of cervical cancers, and Helicobacter pylori, causing duodenal ulceration $(1,2)$, but several other pathogen-disease links have been suggested where data are conflicting or controversial.

Human herpesviruses are widely spread in the population, with the seroprevalence of varicella zoster virus (VZV), Epstein-Barr virus (EBV), cytomegalovirus (CMV), and human herpesvirus 6 (HHV-6) increasing rapidly in the first years of life, whereas herpes simplex virus (HSV) infection generally occurs at more advanced ages (3-6). HSV types 1 and 2, VZV, and HHV-6A are all neurotropic and can cause acute central nervous system (CNS) illness even in immunocompetent hosts (7-10). CMV is less prone to infect neurons but target endothelial cells, microglia, and hematopoietic cells, including those that reside in the brain and could therefore have indirect effects through immune modulation or inflammatory mediators (11).

Alzheimer's disease (AD), with approximately 36.5 million people currently affected worldwide, is the most common form of dementia, causing substantial suffering for patients and a heavy burden on caretakers (12). Whether infectious diseases can be causal, facilitating, or confounding factors in the pathogenesis of $\mathrm{AD}$ is yet to be established. Studies of $\mathrm{AD}$ postmortem brain tissue have shown an increased prevalence of HSV-1 DNA in patients carrying the ApoE $€ 4$ allele and HHV-6 DNA regardless of ApoE genotype (8).

In terms of humoral immune response, it has been shown that serum levels of HSV IgM, but not IgG, antibodies correlates with $\mathrm{AD}(13-15)$. Furthermore, it has been suggested that there is a 
cumulative correlation between a serologic pattern of multiple herpesvirus infections and cognitive decline in patients with vascular disease $(16,17)$. Also, a connection between CMV and AD was made in a combined clinical and postmortem study where CMV IgG levels and IFN- $\gamma$ in cerebrospinal fluid correlated with neuropathologic characteristics of AD (18). This is consistent with the findings in a previous prospective study, where an increased rate of cognitive decline was seen in patients with high levels of CMV IgG (19).

We have previously shown that $\mathrm{AD}$ patients present with a lower frequency of CMV-specific CD8+ T-cells and that $\mathrm{CMV}$-seropositive $\mathrm{AD}$ patients show a more pro-inflammatory peripheral blood mononuclear cell (PBMC) phenotype than both $\mathrm{CMV}$-seronegative $\mathrm{AD}$ patients and $\mathrm{CMV}$-seropositive non-demented (ND) controls $(20,21)$. In this study, we have investigated whether patients with $\mathrm{AD}$ present with a different herpesvirus-specific serologic pattern compared to ND controls, using an in-house multiplex IgG immunoassay with antigens generated by lysis of purified virions from infected cells. Furthermore, we have investigated whether the differences seen in the serologic reactivity pattern could be verified by PCR analysis of PBMCs.

\section{MATERIALS AND METHODS}

\section{Subjects and Sampling Procedure}

A total of $51 \mathrm{AD}$ patients and $52 \mathrm{ND}$ controls were included from a previously described cohort (20). One participant in the $\mathrm{AD}$ group was excluded due to a change in the diagnosis from $\mathrm{AD}$ to frontotemporal dementia, rendering a total of 50 $\mathrm{AD}$ subjects and $52 \mathrm{ND}$ controls. Demographics and cognitive performance of the study groups is described in Table 1. All $\mathrm{AD}$ subjects had recently received a clinical $\mathrm{AD}$ diagnosis in accordance with the NINCDS-ADRDA criteria and DSM-IV criteria. Thus, all patients described a clinical picture of $\mathrm{AD}$ and a CT or MRI scan consistent with the diagnosis, i.e., without significant vascular abnormalities. Subjects in the ND control group had been recruited via local advertising and did not show any frank clinical signs that could suggest the presence of cognitive deficits or complain of any subjective cognitive impairment. Blood samples were acquired by venipuncture, performed at the Memory Disorder Unit at Uppsala University Hospital. Plasma was separated from blood cells through centrifugation, and the samples were frozen at $-20^{\circ} \mathrm{C}$ until analyzed. PBMCs were isolated using BD Vacutainer CPT ${ }^{\mathrm{TM}}$ Cell Preparation Tubes with sodium citrate and frozen in batches of $5 \times 10^{6}$ cells in medium

TABLE 1 | Summary of baseline characteristics in patients with Alzheimer's disease (AD) and non-demented controls (ND).

\begin{tabular}{lcc}
\hline Continuous data reported as mean (SD) & AD $(\mathbf{N}=\mathbf{5 0})$ & ND (N= 52) \\
\hline Age, years & $77.5(6.9)$ & $74.2(7.9)$ \\
Gender, male/female & $28 / 22$ & $23 / 29$ \\
Mini-Mental State Examination score & $19.9(4.8)$ & $\mathrm{NA}$ \\
APOE 64 allele carriers, hetero-/homozygote & $28 / 4$ & $16 / 2$ \\
\hline
\end{tabular}

NA, not available. consisting of $15 \%$ dimethyl sulfoxide and $85 \%$ fetal calf serum. The dementia status of all study participants were blinded during the laboratory work.

This study was carried out in accordance with the Declaration of Helsinki. Written informed consent was obtained from all study participants, together with consent from a close relative if the subject was considered incapable of taking his or her own decision. The study was approved (no. 2009/097) by the Regional Ethical Review Board in Uppsala, Sweden.

\section{Antigens}

The following antigens (Advanced Biotechnologies, Eldersburg, MD, USA) were used for the analyses: herpes simplex type 1 (strain MacIntyre, cat. no. 10-145-000, purified by ultracentrifugation, control antigen: VERO cells, cat. no. 10-508-001), CMV (strain AD169 purified viral lysate, cat. no. 10-144-000, control antigen: human foreskin fibroblasts cells, cat. no. 10-505-001), VZV (strain rod, pelleted virus from supernatant from an infected culture, cat. no. 10-282-500, control antigen: VERO cells), and HHV-6A (GS strain, pelleted virus from supernatant of an infected culture, cat. no. 10-241-500, control antigen: HSB-2 cells, cat. no. 10-529-001). The purified virions were lysed by exposure to the non-ionic detergent Triton-X100 (1\% $\mathrm{w} / \mathrm{v}$ ) for $10 \mathrm{~min}$ at room temperature. Antigens were dialyzed overnight against phosphate buffered saline before coupling. Coupling to beads at lysine positions of the peptides were made using water-soluble carbodiimide according to the procedure described by Luminex Corporation. Between 10 and $30 \mu \mathrm{g}$ of protein was used per coupling, which sufficed for approximately 1,000 tests.

\section{Multiplex Immunoassay}

All antigens were covalently coupled to carboxylated color-coded beads, as previously described by Elfaitouri et al (22). IgG was detected using biotinylated protein G (23). The specificity of the antibody detection was confirmed by using $4 \mu \mathrm{g} / \mathrm{ml}$ biotinylated monoclonal anti-IgG (BioLegend, San Diego, CA, USA, cat. no. 409307). Results are expressed as median fluorescent intensity. StabilGuard (SurModics, Eden Prairie, MN, USA) was used as a sample diluent throughout the process. Samples were diluted $1: 10$, including the preparation steps prior to loading the filter plate. A final bead concentration of 25 beads/ $\mu$ l was used during analysis. All samples and controls were sonicated and vortexed for $20 \mathrm{~s}$ before being added to the bead mixture.

The standard Luminex protocol for indirect antibody capture immunoassay was followed with the previously described adaptations (22). Samples $(100 \mu \mathrm{l})$ were analyzed on a Luminex ${ }^{\circledR} 200^{\mathrm{TM}}$ system, in accordance with the manufacturer's instructions. The StarStation (Applied Cytometry, Sheffield, UK) and xPONENT ${ }^{\circledR}$ (Luminex Corporation, Austin, TX, USA) software were used to analyze the data.

\section{HHV-6 PCR}

In brief, HHV-6 DNA was extracted from 200,000 PBMCs using MagNA Pure LC Total Nucleic Acid Isolation Kit-High Performance (Roche Diagnostics). HHV-6 DNA quantification was performed using a RealStar HHV-6 PCR kit 1.0 (Altona 
Diagnostics) on an ABI 7500 FAST Real-time PCR instrument (Applied Biosystems). The PCR program consisted of 1 cycle at $95^{\circ} \mathrm{C}$ in $10 \mathrm{~min}$ followed by 45 cycles at $95^{\circ} \mathrm{C}$ in $15 \mathrm{~s}$ and $58^{\circ} \mathrm{C}$ in $1 \mathrm{~min}$. To evaluate potential PCR inhibition, an internal control was included in each PCR and detected with a JOE-labeled IC-specific probe. The PCR method differentiates HHV-6A and HHV-6B through a FAM-labeled HHV-6A and a Cy5-labeled HHV-6B-specific probe. From the specification provided by the PCR kit manufacturer, the analytical sensitivity of the PCR assay was calculated to two copies of HHV-6 DNA, but the primer and probe sequences are not given. Subtype specificity of the assay was confirmed by testing cultured HHV-6A GS Strain and HHV6B Z-29 Strain. The specificity of the assay was further verified by testing HSV-1, HSV-2, VZV, CMV, EBV, HHV-7, HHV-8, BK, and JC virus, parvovirus, hepatitis $\mathrm{A}, \mathrm{B}, \mathrm{C}$, and HIV-1.

\section{Statistical Analysis}

$\mathrm{R}$ version 3.0.2 (The R Foundation for Statistical Computing) with packages coin (version 1.1.0) and latticeExtra (version 0.6.26) was used for statistical analysis and graphical output. AD and ND groups were compared using a multivariate Mann-Whitney test. Multiplicity adjustment was done using a permutation-based step-down procedure accounting for the correlation between the test statistics (24).

\section{RESULTS}

\section{Multiplex Immunoassay}

All IgG reactivity data were plotted in a matrix of pairwise comparisons, revealing no obvious patterns of cross-reactivity between the respective sets of antigens (Figure 1). Density plots (Figure 2) showed clustering into seronegative and seropositive populations for CMV and HSV-1. For HHV-6 and VZV, there was no clear separation into subpopulations, most likely due to a very high seroprevalence in the study population.

Alzheimer's disease patients presented with significantly lower HHV-6 IgG reactivity compared to ND controls ( $p=0.02$ after multiplicity adjustment, Figure 2). The numerical difference in CMV IgG between AD and ND groups failed to reach statistical significance ( $p=0.28$ after multiplicity adjustment). Within the AD group, there was no correlation between MMSE score and IgG levels for HHV-6 or CMV (Figure 3). Neither were there any significant differences between $\mathrm{AD}$ and $\mathrm{ND}$ groups with respect to HSV or VZV IgG levels. Both positive and negative results were verified in a logistic regression model including all antibody levels, age, and gender.

To assess the correlation between the whole-virus IgG reactivity in the multiplex assay and microbiologic reference methods, a selected set of samples was also analyzed using single-agent ELISA kits (Focus Diagnostics HerpeSelect HSV IgG, Vidas CMV IgG, Mobitech anti-HHV-6 IgG, and Siemens Enzygnost anti-VZV/IgG). The epitopes created through the in-house lysis of purified virions in the multiplex assay resulted in differences compared to reference methods and illustrated that the assays are not directly interchangeable (Figure 4).

\section{HHV-6 PCR}

As the multiplex immunoassay indicated a possible difference in HHV-6 humoral immunity between AD and ND groups, we proceeded to analyze PBMC samples with a subtype-specific quantitative HHV-6 PCR to establish whether there was a difference in peripheral viral reactivation between groups. A total of 50 $\mathrm{AD}$ and $52 \mathrm{ND}$ subjects were analyzed, rendering $4 \mathrm{HHV}-6 \mathrm{DNA}-$ positive results in the $\mathrm{AD}$ group (8\%) and 4 in the ND group (7.7\%). All positive samples were of HHV-6 subtype B. There was no clear difference in DNA levels between the two groups (Table 2). Two AD and one ND participants presented with DNA levels in the $10^{6}$ copies (per $10^{6}$ cells) range, most likely related to chromosomally integrated HHV-6.

\section{DISCUSSION}

In this study, we illustrate the application of a multiplex immunoassay with in-house-generated antigens to compare IgG reactivity against four human herpesviruses of which some have previously been connected to $\mathrm{AD}$, both seroepidemiologically (13-17) and by the presence of viral DNA in AD brain tissue (25). Although the assay would need additional validation to be useful in a clinical setting for the diagnosis of herpesvirus infections, we believe the current results are valid for the within-study comparison of humoral herpesvirus immunity between AD and ND subjects. Moreover, this alternative methodological approach could provide new insights in addition to the previous studies performed with regular single ELISA assays.

The finding that AD subjects have significantly lower levels of HHV-6 IgG reactivity compared to ND controls is in contrast to the previous findings by Agostini et al., who did not see a correlation between HHV-6 IgG and cognitive performance (26). Also, the fact that demented subjects were found to present with lower IgG toward an agent in the herpesvirus group is different from what is previously known from studies of CMV and HSV-1, where cognitive decline has been associated with higher antibody levels $(14,15,19)$. However, as cell tropism differs within the herpesvirus group, the humoral immune response could have different effects on the AD pathophysiology depending on the type of virus and possibly also the stage of disease.

These findings, suggesting an impaired humoral immunity against HHV-6, could provide an explanation to the more frequent findings of HHV-6 DNA in AD brain tissue, although this study does not give any evidence of causality. The work by Carbone et al. could however give a hint, as they observed an increased risk of progression to $\mathrm{AD}$ in the subjects in the control group that presented with a positive HHV6 PCR on peripheral blood at baseline (25). With an expected seroprevalence of HHV-6 close to $100 \%$ in these age groups, the differences are probably not attributable to total prevalence of chronically persistent HHV-6 infection but rather to differences in humoral immune response. One could speculate on whether decreased antibody levels increase the risk of local CNS HHV-6 reactivation, elevating the inflammatory response that could enhance 


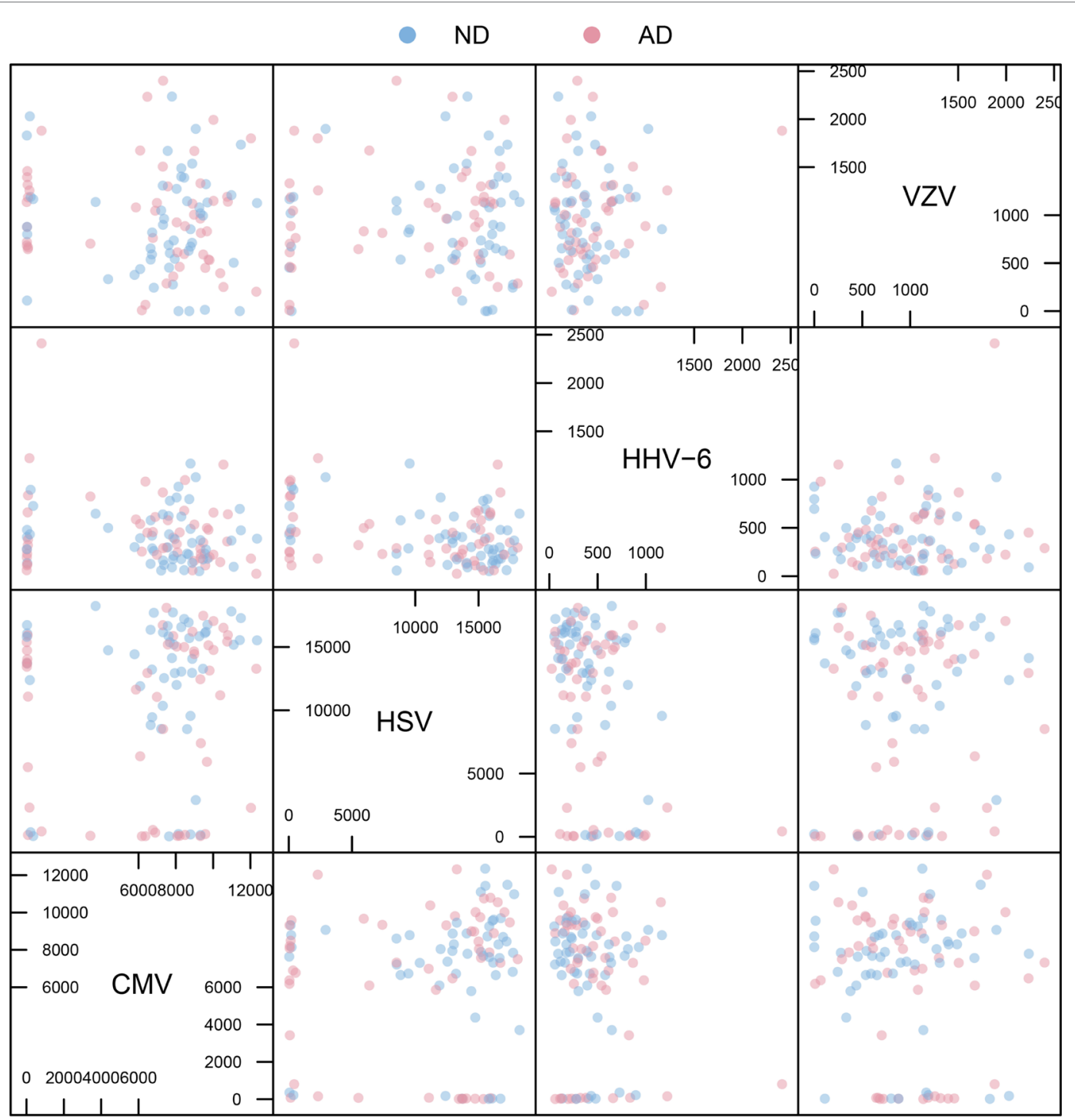

Scatter Plot Matrix

FIGURE 1 | Scatter plot matrix. Pairwise plots for all combinations of antigens, comparing antibody distributions for Alzheimer's disease (AD) and non-demented (ND) groups. The overall absence of strong diagonal patterns indicates no obvious cross-reactivity between antibodies.

AD pathology (27). Other possible explanations include age differences between $\mathrm{AD}$ and ND groups at the time of primary infection or more profound immunologic changes in $\mathrm{AD}$ affecting herpesvirus immunity in general.

As there was no difference in HHV-6 DNA in PBMC between the groups, and all positive samples were of subtype $B$, the results do not support the hypothesis that peripheral reactivation of HHV- 6 of any subtype is implicated in AD pathogenesis. However, as we did not analyze brain tissue samples, we cannot exclude local HHV-6 reactivation. These results are in conflict with a previous study by Carbone et al. who found HHV-6 DNA five times more frequently in peripheral blood leukocytes from AD subjects compared to controls (25).
Array-based multiplex techniques have made it possible to measure antibodies to many infectious agents simultaneously with a small sample volume, allowing a rapid syndromecentered overview of pathogen antibodies, and provide better control of false-positive reactions due to cross-reactivity than what can be achieved with single assays. It has been previously reported that multiplexing serologic assays can introduce negative matrix effects caused by interindividual variations in serum lipids, proteins, heterophilic antibodies, and immune complexes $(28,29)$. However, the protocol used in this study uses a lower concentration of carrier proteins and has so far proven robust. We chose to measure only IgG reactivity as the relevance of IgM, especially outside the clinical context of paired 

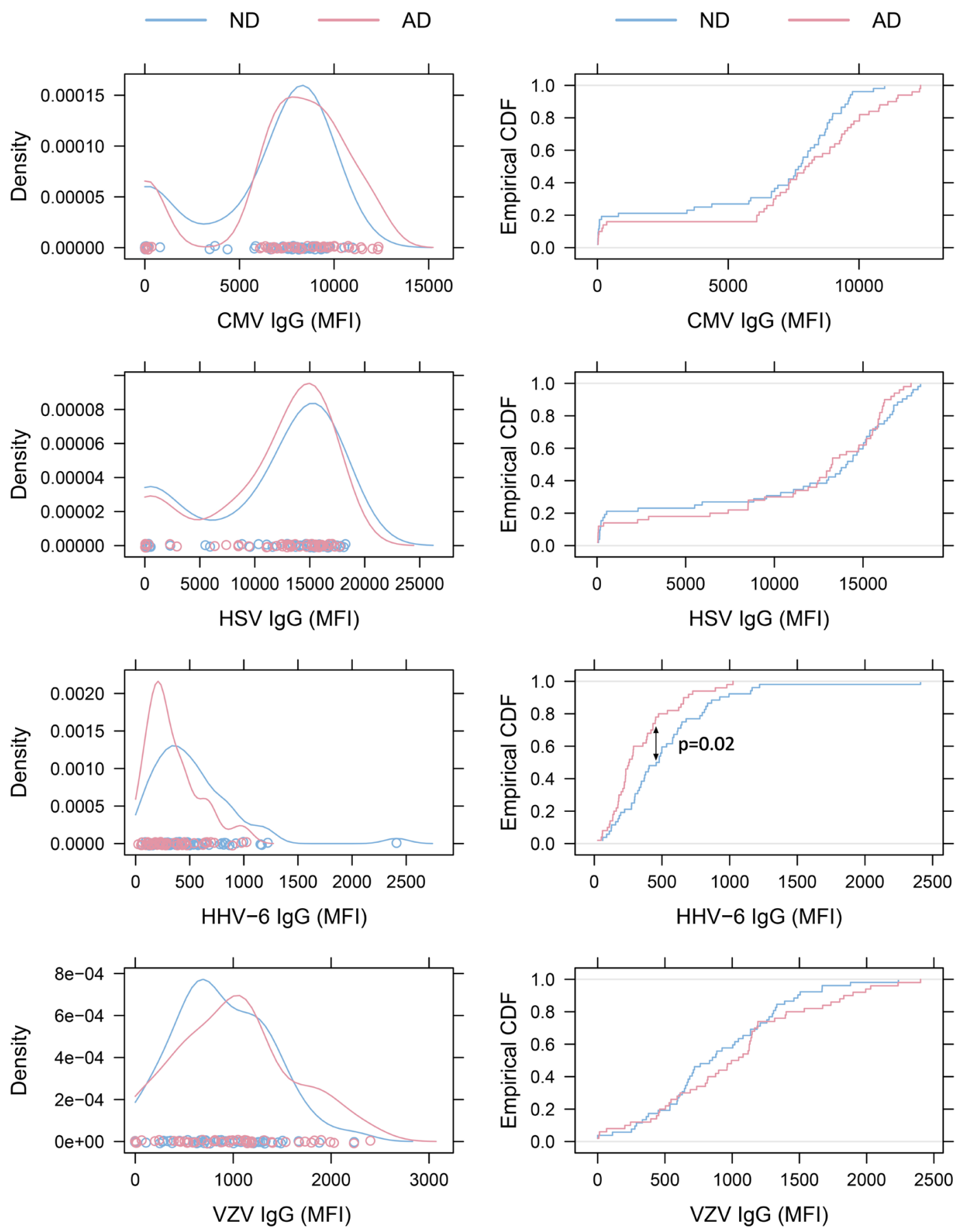

FIGURE 2 | Density plots and empirical cumulative distribution functions (ECDF). Left: density plots of virus-specific antibody levels. The distributions for cytomegalovirus (CMV) and herpes simplex virus (HSV)-1 illustrate clustering of subjects into seronegative and seropositive populations. No obvious clustering was seen in human herpesvirus 6 (HHV-6) and varicella zoster virus (VZV) plots, as expected when seroprevalence is close to 100\%. Right: ECDF plots illustrating that Alzheimer's disease (AD) patients present with lower HHV-6 antibody levels than non-demented (ND) controls ( $p=0.02$ with Bonferroni-Holm correction).

sampling in primary infection, which is limited not only by the methodological issues mentioned above but also by the natural cross-reactivity between different members of the herpesvirus group due to their structural similarity that affects IgM more than $\operatorname{IgG}(30,31)$.
As the multiplex serologic protocol used in this study has not been extensively validated against the gold standard methods used in clinical practice, any comparison with these should be made with caution. Also, the serologic distinction between HHV-6A and HHV-6B is difficult to make due to cross-reactivity, so the 

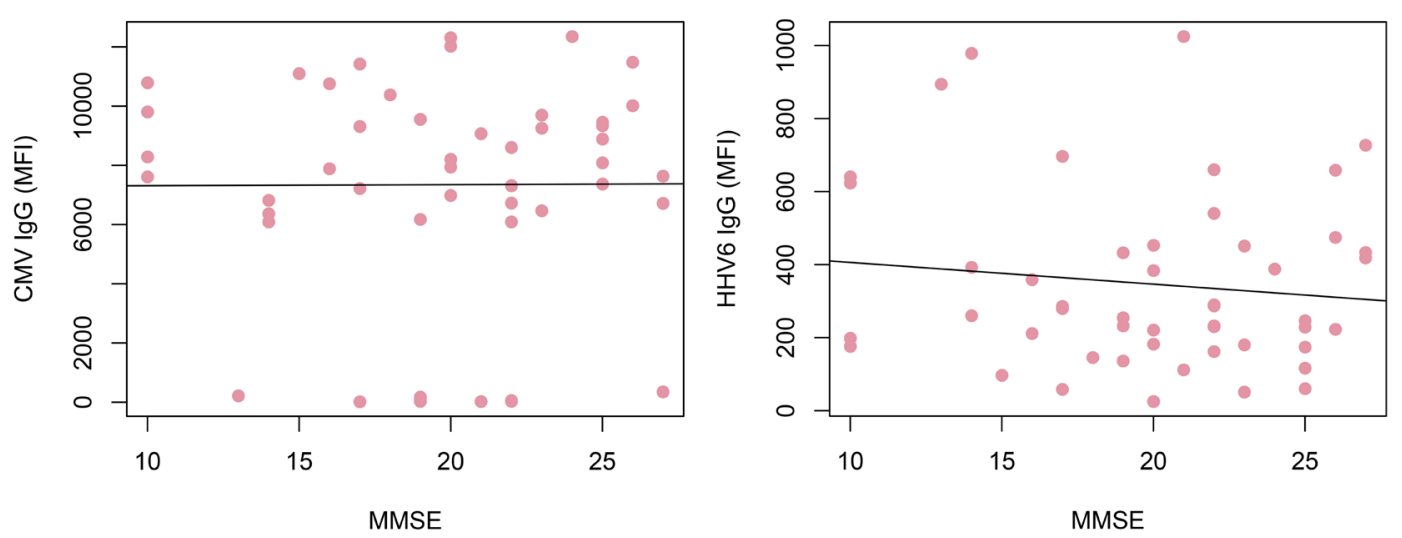

FIGURE 3 | Correlation of IgG reactivity and cognitive performance in Alzheimer's disease (AD) patients. No correlation could be found between cytomegalovirus (CMV) or human herpesvirus $6(\mathrm{HHV}-6)$ IgG levels and MMSE score. Only AD patients were included.
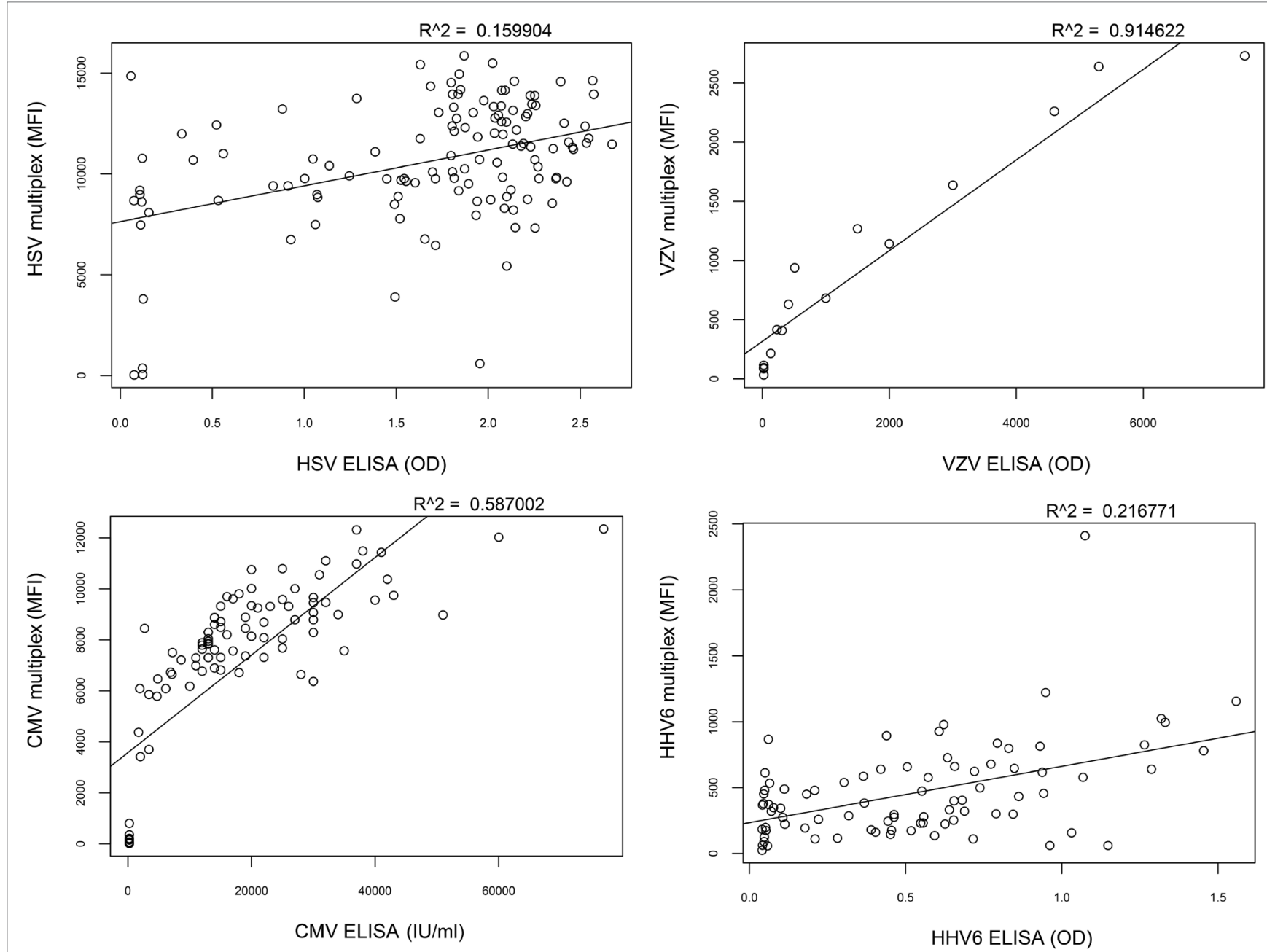

FIGURE 4 | Correlation between multiplex assay and reference methods. The correlation of IgG reactivity between the multiplex assay and standard ELISA is low for herpes simplex virus (HSV) $\left(R^{2}=0.16\right)$ and human herpesvirus $6(\mathrm{HHV}-6)\left(R^{2}=0.22\right)$, intermediate for cytomegalovirus $(\mathrm{CMV})\left(R^{2}=0.59\right)$, and high for varicella zoster virus (VZV) $\left(R^{2}=0.91\right)$. 
TABLE 2 | Subtype-specific HHV-6 PCR.

\begin{tabular}{lcccc}
\hline Gender & Age & Dementia status & HHV-6 DNA & Subtype \\
\hline Male & 68 & Alzheimer's disease (AD) & $4 \times 10^{6}$ & $\mathrm{~B}$ \\
Male & 76 & AD & $2 \times 10^{6}$ & $\mathrm{~B}$ \\
Male & 80 & AD & $9 \times 10^{3}$ & $\mathrm{~B}$ \\
Female & 72 & AD & $8 \times 10^{1}$ & $\mathrm{~B}$ \\
Female & 72 & Non-demented (ND) & $6 \times 10^{1}$ & $\mathrm{~B}$ \\
Male & 51 & ND & $2 \times 10^{6}$ & $\mathrm{~B}$ \\
Male & 75 & ND & $1 \times 10^{2}$ & $\mathrm{~B}$ \\
Female & 75 & ND & $2 \times 10^{4}$ & $\mathrm{~B}$ \\
\hline
\end{tabular}

Overview of $A D$ and ND subjects positive for HHV-6 DNA in PBMCs. DNA levels are expressed as copies per million cells.

identified differences are likely to be driven by a large contribution of HHV6-B antibodies.

Although several other members of the human herpesvirus family have been previously correlated with cognitive decline, we could not-with the exception of HHV-6-find any serological evidence supporting the hypothesis that infections with HSV, $\mathrm{VZV}$, or CMV correlate with $\mathrm{AD}$. The precision of these negative results is, however, limited by the sample size in this study. Whether HHV-6 is involved in the pathogenesis of AD or other neurodegenerative diseases remains to be elucidated in future studies.

\section{REFERENCES}

1. Marshall BJ, McGechie DB, Rogers PA, Glancy RJ. Pyloric Campylobacter infection and gastroduodenal disease. Med J Aust (1985) 142(8):439-44.

2. Walboomers JM, Jacobs MV, Manos MM, Bosch FX, Kummer JA, Shah KV, et al. Human papillomavirus is a necessary cause of invasive cervical cancer worldwide. J Pathol (1999) 189(1):12-9. doi:10.1002/ (SICI)1096-9896(199909)189:1<12::AID-PATH431>3.0.CO;2-F

3. Ahlfors K. IgG antibodies to cytomegalovirus in a normal urban Swedish population. Scand J Infect Dis (1984) 16(4):335-7. doi:10.3109/00365548 409073957

4. Kangro HO, Osman HK, Lau YL, Heath RB, Yeung CY, Ng MH. Seroprevalence of antibodies to human herpesviruses in England and Hong Kong. J Med Virol (1994) 43(1):91-6. doi:10.1002/jmv.1890430117

5. Pebody RG, Andrews N, Brown D, Gopal R, De Melker H, François G, et al. The seroepidemiology of herpes simplex virus type 1 and 2 in Europe. Sex Transm Infect (2004) 80(3):185-91. doi:10.1136/sti.2003.005850

6. Svahn A, Berggren J, Parke A, Storsaeter J, Thorstensson R, Linde A. Changes in seroprevalence to four herpesviruses over 30 years in Swedish children aged 9-12 years. J Clin Virol (2006) 37(2):118-23. doi:10.1016/j. jcv.2006.07.012

7. Gordon B, Selnes OA, Hart J Jr, Hanley DF, Whitley RJ. Long-term cognitive sequelae of acyclovir-treated herpes simplex encephalitis. Arch Neurol (1990) 47(6):646-7. doi:10.1001/archneur.1990.00530060054017

8. Lin WR, Wozniak MA, Cooper RJ, Wilcock GK, Itzhaki RF. Herpesviruses in brain and Alzheimer's disease. J Pathol (2002) 197(3):395-402. doi:10.1002/ path. 1127

9. Gilden D, Cohrs RJ, Mahalingam R, Nagel MA. Neurological disease produced by varicella zoster virus reactivation without rash. Curr Top Microbiol Immunol (2010) 342:243-53. doi:10.1007/82_2009_3

10. Mannonen L, Herrgard E, Valmari P, Rautiainen P, Uotila K, Aine MR, et al. Primary human herpesvirus-6 infection in the central nervous system can cause severe disease. Pediatr Neurol (2007) 37(3):186-91. doi:10.1016/j. pediatrneurol.2007.05.011

11. van Den Pol AN, Mocarski E, Saederup N, Vieira J, Meier TJ. Cytomegalovirus cell tropism, replication, and gene transfer in brain. J Neurosci (1999) 19(24):10948-65.

\section{AUTHOR CONTRIBUTIONS}

GW, B-ME, JB, MI, and LL-substantial contributions to the conception or design of the work. GW, JB, B-ME, ZY, and MI-acquisition, analysis, or interpretation of data for the work. All authors-drafting the work or revising it critically for important intellectual content. All authors-final approval of the version to be published. All authors-agreement to be accountable for all aspects of the work in ensuring that questions related to the accuracy or integrity of any part of the work are appropriately investigated and resolved.

\section{ACKNOWLEDGMENTS}

We are very grateful for the invaluable practical and intellectual assistance from Käthe Ström and Rose-Marie Brundin at the Memory Disorder Unit at Uppsala University Hospital and Johan Lindbäck at Uppsala Clinical Research Center. Special thanks go to Amal Elfaitouri for her contributions in the lab.

\section{FUNDING}

This study has been funded by the Family Olinder-Nielsen's Foundation and Uppsala University.

12. Sosa-Ortiz AL, Acosta-Castillo I, Prince MJ. Epidemiology of dementias and Alzheimer's disease. Arch Med Res (2012) 43(8):600-8. doi:10.1016/j. arcmed.2012.11.003

13. Letenneur L, Peres K, Fleury H, Garrigue I, Barberger-Gateau P, Helmer C, et al. Seropositivity to herpes simplex virus antibodies and risk of Alzheimer's disease: a population-based cohort study. PLoS One (2008) 3(11):e3637. doi:10.1371/journal.pone.0003637

14. Lovheim H, Gilthorpe J, Adolfsson R, Nilsson LG, Elgh F. Reactivated herpes simplex infection increases the risk of Alzheimer's disease. Alzheimers Dement (2015) 11(6):593-9. doi:10.1016/j.jalz.2014.04.522

15. Lovheim H, Gilthorpe J, Johansson A, Eriksson S, Hallmans G, Elgh F. Herpes simplex infection and the risk of Alzheimer's disease - a nested case-control study. Alzheimers Dement (2015) 11(6):587-92. doi:10.1016/j. jalz.2014.07.157

16. Strandberg TE, Pitkala K, Eerola J, Tilvis R, Tienari PJ. Interaction of herpesviridae, APOE gene, and education in cognitive impairment. Neurobiol Aging (2005) 26(7):1001-4. doi:10.1016/j.neurobiolaging.2004.09.008

17. Strandberg TE, Pitkala KH, Linnavuori KH, Tilvis RS. Impact of viral and bacterial burden on cognitive impairment in elderly persons with cardiovascular diseases. Stroke (2003) 34(9):2126-31. doi:10.1161/01. STR.0000086754.32238.DA

18. Lurain NS, Hanson BA, Martinson J, Leurgans SE, Landay AL, Bennett DA, et al. Virological and immunological characteristics of human cytomegalovirus infection associated with Alzheimer disease. J Infect Dis (2013) 208(4):564-72. doi:10.1093/infdis/jit210

19. Aiello AE, Haan M, Blythe L, Moore K, Gonzalez JM, Jagust W. The influence of latent viral infection on rate of cognitive decline over 4 years. J Am Geriatr Soc (2006) 54(7):1046-54. doi:10.1111/j.1532-5415.2006. 00796.x

20. Westman G, Lidehall AK, Magnusson P, Ingelsson M, Kilander L, Lannfelt L, et al. Decreased proportion of cytomegalovirus specific CD8 T-cells but no signs of general immunosenescence in Alzheimer's disease. PLoS One (2013) 8(10):e77921. doi:10.1371/journal.pone.0077921

21. Westman G, Berglund D, Widen J, Ingelsson M, Korsgren O, Lannfelt L, et al. Increased inflammatory response in cytomegalovirus seropositive patients with Alzheimer's disease. PLoS One (2014) 9(5):e96779. doi:10.1371/journal. pone.0096779 
22. Elfaitouri A, Herrmann B, Bolin-Wiener A, Wang Y, Gottfries CG, Zachrisson $\mathrm{O}$, et al. Epitopes of microbial and human heat shock protein 60 and their recognition in myalgic encephalomyelitis. PLoS One (2013) 8(11):e81155. doi:10.1371/journal.pone.0081155

23. Akerstrom B, Brodin T, Reis K, Bjorck L. Protein G: a powerful tool for binding and detection of monoclonal and polyclonal antibodies. J Immunol (1985) 135(4):2589-92.

24. Westfall PH, Young SS. Resampling-Based Multiple Testing: Examples and Methods for p-Value Adjustment. New York, NY: John Wiley \& Sons (1993).

25. Carbone I, Lazzarotto T, Ianni M, Porcellini E, Forti P, Masliah E, et al. Herpes virus in Alzheimer's disease: relation to progression of the disease. Neurobiol Aging (2013) 35(1):122-9. doi:10.1016/j.neurobiolaging.2013.06.024

26. Agostini S, Mancuso R, Baglio F, Cabinio M, Hernis A, Guerini FR, et al. Lack of evidence for a role of HHV-6 in the pathogenesis of Alzheimer's disease. J Alzheimers Dis (2015) 49(1):229-35. doi:10.3233/ JAD-150464

27. Blasko I, Marx F, Steiner E, Hartmann T, Grubeck-Loebenstein B. TNFalpha plus IFNgamma induce the production of Alzheimer beta-amyloid peptides and decrease the secretion of APPs. FASEB J (1999) 13(1):63-8.

28. Tate J, Ward G. Interferences in immunoassay. Clin Biochem Rev (2004) 25(2):105-20.

29. Dias D, Van Doren J, Schlottmann S, Kelly S, Puchalski D, Ruiz W, et al. Optimization and validation of a multiplexed Luminex assay to quantify antibodies to neutralizing epitopes on human papillomaviruses 6 , 11, 16, and 18. Clin Diagn Lab Immunol (2005) 12(8):959-69. doi:10.1128/ CDLI.12.8.959-969.2005

30. Edson CM, Hosler BA, Respess RA, Waters DJ, Thorley-Lawson DA. Crossreactivity between herpes simplex virus glycoprotein $\mathrm{B}$ and a 63,000-dalton varicella-zoster virus envelope glycoprotein. J Virol (1985) 56(1):333-6.

31. Lang D, Vornhagen R, Rothe M, Hinderer W, Sonneborn HH, Plachter B. Cross-reactivity of Epstein-Barr virus-specific immunoglobulin $\mathrm{M}$ antibodies with cytomegalovirus antigens containing glycine homopolymers. Clin Diagn Lab Immunol (2001) 8(4):747-56. doi:10.1128/CDLI.8.4.747-756.2001

Conflict of Interest Statement: The authors declare that the research was conducted in the absence of any commercial or financial relationships that could be construed as a potential conflict of interest.

Copyright (C) 2017 Westman, Blomberg, Yun, Lannfelt, Ingelsson and Eriksson. This is an open-access article distributed under the terms of the Creative Commons Attribution License (CC BY). The use, distribution or reproduction in other forums is permitted, provided the original author(s) or licensor are credited and that the original publication in this journal is cited, in accordance with accepted academic practice. No use, distribution or reproduction is permitted which does not comply with these terms. 